\title{
Mathematical Modeling and Analysis of Tribological Properties of AA6063 Aluminum Alloy Reinforced with Fly Ash by Using Response Surface Methodology
}

\author{
Alaa Mohammed Razzaq ${ }^{1,2}$, Dayang Laila Majid ${ }^{3, *}$, Mohamad Ridzwan Ishak ${ }^{3}$ and \\ Uday Muwafaq Basheer ${ }^{4,5}$ (D) \\ 1 Oil Products Distribution Company, Iraq Ministry of Oil, Baghdad 10022, Iraq; alaaupm@gmail.com \\ 2 Department of Materials Technology Engineering, Technical Engineering College-Baghdad, Middle \\ Technical University, Baghdad 10074, Iraq \\ 3 Department of Aerospace Engineering, Faculty of Engineering, Universiti Putra Malaysia, Serdang 43400, \\ Malaysia; mohdridzwan@upm.edu.my \\ 4 Faculty of Mechanical Engineering, Universiti Teknologi Malaysia, Johor Bahru 81310, Malaysia; \\ ummb2008@gmail.com \\ 5 Centre for Advanced Composite Materials (CACM), Institute for Vehicle Systems and Engineering, \\ Universiti Teknologi Malaysia, Skudai 81310, Malaysia \\ * Correspondence: dlaila@upm.edu.my
}

Received: 12 February 2020; Accepted: 1 April 2020; Published: 16 May 2020

check for updates

\begin{abstract}
Lightweight, high-strength metal matrix composites have attracted considerable interest because of their attractive physical, mechanical and tribological properties. Moreover, they may offer distinct advantages due to good strength and wear resistance. In this research, AA6063 was reinforced with FA particles using compocasting methods. The effects of fly ash content, load, sliding speed and performance tribology of AA6063 -FA composite were evaluated. Dry sliding wear tests were carried out according to experimental design using the pin-on-disc method with three different loads $(24.5,49$ and $73.5 \mathrm{~N})$ and three speeds $(150,200$ and $250 \mathrm{rpm})$ at room temperature. Response surface methodology (RSM) was used to analyze the influence of the process parameters on the tribological behavior of the composites. The surface plot showed that the wear rate increased with increasing load, time and sliding velocity. In contrast, the friction coefficient decreased with increasing these parameters. Optimal models for wear rate and friction coefficient showed appropriate results that can be estimated, hence reducing wear testing time and cost.
\end{abstract}

Keywords: AA6063; fly ash; response surface methodology; tribological properties; wear rate; friction coefficient

\section{Introduction}

Light-weight metal matrix composites (MMCs) have paved the way to replace steels and reduce greenhouse effects, hence they are used in various applications. A particular example is discontinuous particulate reinforced aluminum composites (DPAMCs), employed in automotive, aerospace and defense sectors [1]. DPAMCs using high-strength refractory particle reinforcements such as $\mathrm{SiC}, \mathrm{TiC}$, $\mathrm{B}_{4} \mathrm{C}, \mathrm{Al}_{2} \mathrm{O}_{3}, \mathrm{MgO}, \mathrm{TiO}_{2}$ were found to improve wear properties; attempts were undertaken to model wear behavior effectively. The modeling involves the process of evaluating the relationship between two or more process variables, as well as with the response variable. To be able to do so effectively, requires a mathematical model that is able to predict the response outcome based on various effects of the process variables [2]—especially in the evaluation of material properties. Techniques such as 
multiple regressions and artificial neural networks were among those applied to build mathematical model. Mechanical and tribological properties can be also predicted by employing other statistical tools, e.g., design of experiments, analysis of variance (ANOVA) and regression analysis [3-5]. Typically for wear tests, the process variables are the load, sliding speed, time and the reinforcement content.

Kumar et al. [6] investigated the size range of fly ash FA particles on dry-sliding wear behavior of aluminum composites. They observed that the wear and friction coefficient of the composites were influenced by sliding speed, reinforcement content and applied load. They developed a mathematical model for prediction of wear rate and the friction coefficient of aluminum composites reinforced with fly ash while the adequacy of the model is evaluated using ANOVA. Rajmohan et al. [7] observed that wear rate increased with increased load. They employed analysis variance ANOVA to analyze the wear behavior of the composite. They found that load is a significant factor in the wear performance of the composite. Magibalan et al. [8] reported that AA8011 composite with $12 \%$ fly ash produced lower wear rates and increased hardness with a value of $63.37 \mathrm{VHN}$. They successfully developed a regression model that can predict the wear rate of cast AA8011-12\% FA composites up to 95\% confidence levels, within the limits of investigation. Normal load, time and sliding velocity were shown to have a strong influence on the wear rate of the composites.

Similarly, Mandaletal et al. [9] predicted the wear behavior of metal matrix composites using regression methods and significance of wear factors using ANOVA method. The increase of parameter was also done by style trained software package. Their work suggested that response surface methodology may be suitable to evaluate the wear performance of combined rolling action and sliding. Moreover, Monikandan et al. [10] presented the tribological properties of mono AA6061-10 $\mathrm{wt} \% \mathrm{~B}_{4} \mathrm{C}$ and hybrid AA6061-10 wt\% B4C-7.5 wt\% Gr composites which were proposed as potential substitute for aluminum alloys used in automotive engines. A full factorial experimental design was conducted, and their findings suggested that the wear loss increased with sliding distance and applied load, while the coefficient of friction also increased with increase in applied load. In addition, the ANOVA analysis revealed the statistically and physically significant factors that influence the wear loss and friction coefficient. Processing-wise, AA6061-15\%TiC aluminum matrix composites were produced by the stir casting method [11]. An empirical relationship incorporating stir casting parameters was developed for predicting ultimate tensile stress. A lower or higher combination of these parameters resulted in lower ultimate tensile stress. In this work, a compocasting technique that utilized a lower processing temperature compared to stir casting method was employed, where the lower temperature aided in reducing interfacial reactions.

The aim of the current work is to develop models to predict wear rate and coefficient of friction as functions of important wear variables. The influences of control factors such as fly ash content, load and sliding speed on wear rate and friction coefficient of AA6063-FA composites prepared by compocasting technique were experimentally evaluated considering design of experimental DOEbased central composite design (CCD) technique. Full quadratic RSM based predictive models for $\mathrm{W}_{\mathrm{r}}$ and $C_{r}$ were developed and subsequently validated with experimental results.

\section{Experimental}

\subsection{Composites Fabrication}

AA6063 alloy was selected as the matrix material. The AA6063-FA composites were fabricated by compocasting technique with wt $\%$ FA $(0-12 \%)$ with the average particle size of FA particles $45 \mu \mathrm{m}$. The manufacturing process, metallographic of the composite, mechanical properties and its XRD spectra are available in an earlier works $[12,13]$. For each sample the experiment was conducted three times and the average of closely repeatable test values were registered as wear rate and coefficient of friction for composites, that it has explained in previous published papers [14,15]. Chemical composition of AA6063 and FA are presented in Tables 1 and 2 respectively [16]. 
Table 1. Chemical composition of tested AA6063 in wt\% [16].

\begin{tabular}{cccccccccc}
\hline Elements & $\mathbf{C u}$ & $\mathbf{F e}$ & $\mathbf{M g}$ & $\mathbf{M n}$ & $\mathbf{S i}$ & $\mathbf{T i}$ & $\mathbf{Z n}$ & $\mathbf{C r}$ & $\mathbf{A l}$ \\
\hline $\mathrm{wt} \%$ & $<0.01$ & 0.19 & 0.51 & 0.04 & 0.86 & 0.008 & 0.01 & 0.01 & Balance \\
\hline
\end{tabular}

Table 2. Chemical composition of fly ash (FA) in wt\% [16].

\begin{tabular}{cccccccccc}
\hline Elements & $\mathrm{SiO}_{2}$ & $\mathrm{Al}_{2} \mathrm{O}_{3}$ & $\mathrm{Fe}_{2} \mathrm{O}_{3}$ & $\mathrm{TiO}_{2}$ & $\mathrm{~K}_{\mathbf{2}} \mathrm{O}$ & $\mathrm{CaO}$ & $\mathrm{MgO}$ & $\mathrm{Na}_{2} \mathrm{O}$ & $\mathrm{CuO}$ \\
\hline $\mathrm{wt} \%$ & 59.98 & 19.09 & 2.78 & 1.14 & 1.09 & 0.63 & 0.38 & 0.34 & 0.01 \\
\hline
\end{tabular}

\subsection{Statistical Analysis Using Surface Response Method SRM}

The data obtained from the wear tests on the AA6063-FA composites was evaluated in Design Expert V10, Design of Experiments/ statistical analysis software using the Response Surface Method (RSM). Two models were developed, one for the wear rate and the other for the coefficient of friction. The $\mathrm{F}$ value is a ratio of the model and residual variance. If the ratio is near to the value of 1 , then it means that the term has a remarkable influence on the response. Likewise, a $p$-value larger than 0.10 indicated that the term has an insignificant effect [17].

The analysis of variance ANOVA technique was employed in analyzing the wear performance of AA6063-FA composites subjected to important controlled parameters. In current study FA was observed as a remarkable contributor in the wear performance of the composites. The robustness of the developed model is typically checked using ANOVA technique [18-20]. In this technique, the F ratio of the developed model that was computed must be lower than the standard tabulated value of $\mathrm{F}$ ratio for a desired level of confidence (say 95\%) in order for the model to be satisfactory within that particular confidence limit. Furthermore, the coefficient of correlation ' $r$ ' was utilized in finding the closeness of predicted and experimental values which is described by the following Equations described by Kumar and Balasubramanian [18]:

$$
\begin{gathered}
\mathrm{r}^{2}=\frac{\text { explained variation }}{\text { total variation }}=\frac{\Sigma\left(W_{r p}-W_{r a}\right)^{2}}{\Sigma\left(W_{r e}-W_{r a}\right)^{2}} \\
\mathrm{r}^{2}=\frac{\text { explained variation }}{\text { total variation }}=\frac{\Sigma\left(F r_{p}-F r_{a}\right)^{2}}{\Sigma\left(F r_{e}-F r_{a}\right)^{2}}
\end{gathered}
$$

where $W_{r p}, F_{r p}$ are the predicted wear rate and coefficient of friction respectively for the given experimental wear rate, $W_{r e}$ and coefficient of friction $F_{r e}$, for the corresponding average of experimental wear rate $W_{r a}$ and average coefficient of friction $F_{r a}$ respectively.

\subsection{Experimental Design}

RSM was used to model the wear rate and friction coefficient of AA6063-FA composite material. The response function representing the variables, namely, FA content, sliding speed and applied load can be expressed as [21,22] $Y=f(F A, S, L)$. The response surface $Y$ for the $k$ parameter is represented in a second order polynomial regression equation, presented as the following:

$$
Y=b_{0}+\sum_{i=1}^{k} b_{i} x_{i}+\sum_{\substack{i=1 \\ i \neq j}}^{k} b_{i} x_{i}^{2}+\sum_{i \neq j}^{k} b_{i j} x_{i} x_{j}
$$

Expanding the polynomial for three factors will give the equation:

$$
Y=b_{0}+b_{1} F A+b_{2} L+b_{3} S+b_{11} F A^{2}+b_{22} L^{2}+b_{33} S^{2}+b_{12} F A L+b_{13} F A S+b_{23} L S
$$


where $b_{0}$ is the average of responses and $b_{1}, b_{2}, b_{3}, b_{12}, b_{13}$ and $b_{23}$ are the coefficients of response dependent upon the respective main and interaction effects of parameters.

From the factorial design, the combined effects of all parameters will result in an empirical relationship between the wear rate and coefficient of friction with the designated parameters which are the fly ash content $(F A)$, load $(L)$ and sliding speed $(S)$. The multiple regression technique used to develop the mathematical model to formulate the influence of the parameters on both responses were achieved via design of experiments analysis software, Design-Expert V10.0.

Feasible limits of all three factors were determined and these are presented in Table 3.

Table 3. Levels of factors.

\begin{tabular}{ccccccccccc}
\hline No. & Factor & Notation & Unit & \multicolumn{7}{c}{ Levels } \\
\hline 1 & Fly ash content & FA & wt $\%$ & 0 & 2 & 4 & 6 & 8 & 10 & 12 \\
\hline 2 & Load & L & N & 24.5 & 49 & 73.5 & - & - & - & - \\
\hline 3 & Sliding speed & S & Rpm & 150 & 200 & 250 & - & - & - & - \\
\hline
\end{tabular}

There were 63 experimental response values of various combination of factors obtained and used to formulate the response function (wear rate and coefficient of friction) as shown in Table A1 (Appendix A) and also as input into the Design-Expert V10.0 software. The highlighted results (Appendix A), which represent $20 \%$ of the total data, was not used in the model construction process. This data were utilized in verification of the proposed empirical model. The rest of the data were introduced in full factorial design using response surface method with user-defined choice. The software then automatically will evaluate all possible combinations of the factors and produce results for the significant and aliased model terms.

The design summary of the problem is tabulated in Table 4 , which shows the summary of the input information and setting required to starting the analysis. In summary, the methods of the current work encompass a quantitative (wear test) and statistical analyses (randomized RSM approach), whereby the statistical method provide a means to assess the effect of all three factors, namely the fly ash content $(F A)$, load $(L)$ and sliding speed $(S)$ on the wear properties with a quadratic design model.

Table 4. Factorial design summary (Design-Expert V10.0).

\begin{tabular}{|c|c|c|c|c|c|c|c|c|c|c|c|}
\hline Factor & Name & Units & Type & Subtype & Min & Max & \multicolumn{2}{|c|}{ Coded Values } & Mean & $\begin{array}{l}\text { Std. } \\
\text { Dev. }\end{array}$ & \\
\hline A & Fly ash content & $w t \%$ & Numeric & Discrete & 0 & 12 & $-1.000=0$ & $1.000=12$ & 6.15686 & 4.05646 & \\
\hline B & Sliding speed & Rpm & Numeric & Discrete & 150 & 250 & $-1.000=150$ & $1.000=250$ & 197.059 & 40.5114 & \\
\hline C & Load & $\mathrm{N}$ & Numeric & Discrete & 24.5 & 73.5 & $-1.000=24.5$ & $1.000=73.5$ & 49.4804 & 19.898 & \\
\hline Response & Name & Units & Obs & Analysis & Min & Max & Mean & Std. Dev. & Ratio & Trans & Model \\
\hline R1 & Wear rate & $\mathrm{mm}^{3} / \mathrm{m}$ & 51 & Polynomial & 3.4623 & 13.3471 & 7.63128 & 2.44359 & 3.85498 & None & Quadratic \\
\hline R2 & Coefficient of $f_{1}$ & ction & 51 & Polynomial & 0.1085 & 0.4723 & 0.236767 & 0.0830769 & 4.353 & None & Quadratic \\
\hline
\end{tabular}

\section{Results and Discussion}

\subsection{Statistical Analyses}

In this section, the effect of FA content, sliding speed and applied load on wear rate and coefficient of friction are discussed. RSM was applied to evaluate and develop models of wear rate and friction coefficient of AA6063-FA composites.

In an attempt to obtain a model with better performance than the one given by the quadratic model of the process, a cubic model equation was developed, but owing to the fact that the developed cubic model was found to be aliased in nature, its model expression in terms of the actual factors was not given by the Design Expert. However, the aliased cubic model, the mathematical expression of which was not available, was still analyzed for variance to see if actually increasing order of model had any effect on the response statistically. 
The models summary statistics given in Tables 5 and 6 show that the quadratic models were suggested according to the statistical evaluation of different models. The software also revealed that the cubic order model was aliased for the ranges of the data obtained. The quadratic model was used according to the value of R-squared $(0.9791,0.9818)$ for wear rate and coefficient of friction model respectively.

Table 5. Statistical summary of wear rate model.

\begin{tabular}{ccccccc}
\hline Source & $\begin{array}{c}\text { Std. } \\
\text { Dev. }\end{array}$ & R-Squared & $\begin{array}{c}\text { Adjusted } \\
\text { R-Squared }\end{array}$ & $\begin{array}{c}\text { Predicted } \\
\text { R-Squared }\end{array}$ & PRESS & Recommendation \\
\hline Linear & 0.60 & 0.9437 & 0.9401 & 0.9338 & 19.76 & \\
2FI & 0.48 & 0.9656 & 0.9609 & 0.9548 & 13.50 & \\
Quadratic & 0.39 & 0.9791 & 0.9745 & 0.9658 & 10.20 & Suggested \\
Cubic & 0.36 & 0.9858 & 0.9784 & 0.9633 & 10.97 & Aliased \\
\hline
\end{tabular}

Table 6. Statistical Summary of Coefficient of Friction Model.

\begin{tabular}{ccccccc}
\hline Source & $\begin{array}{c}\text { Std. } \\
\text { Dev. }\end{array}$ & R-Squared & $\begin{array}{c}\text { Adjusted } \\
\text { R-Squared }\end{array}$ & $\begin{array}{c}\text { Predicted } \\
\text { R-Squared }\end{array}$ & PRESS & Recommendation \\
\hline Linear & 0.024 & 0.9214 & 0.9164 & 0.9043 & 0.033 & \\
2FI & 0.020 & 0.9483 & 0.9412 & 0.9242 & 0.026 & Suggested \\
Quadratic & 0.012 & 0.9818 & 0.9778 & 0.9699 & 0.010 & Aliased \\
Cubic & 0.009406 & 0.9915 & 0.9872 & 0.9769 & 0.007958 & \\
\hline
\end{tabular}

\subsection{Modeling and Analysis of Variance of Wear Rate}

The design of experiment software with response surface method was used to statistically study the effect of fly ash (FA), sliding speed (S) and applied load (L) on the wear rate of AA6063-FA composites and to build an empirical model for Wear rate based on the effects of these factors. The sequential F-test was conducted for testing the significance of the regression model.

The step-wise regression method was utilized for the wear rate model with the entire potential combinations of the control factors with exception of the cubic terms since these terms were aliased for the data ranges obtained. The selected terms along with the step-wise regression method led to the elimination of the less significant model terms automatically. Table 7 shows the analysis of variance generated for wear rate model. The model F-value of 213.395 confirms the significance of the model. A $p$-value of 0.0001 was indicative that there was a low chance of F-value which could occur as result of noise. The predicted $R^{2}$ of 0.9658 , which represent the measure of the amount of variation about the mean explained by the model agrees well with the adjusted $R^{2}$ of 0.9745 . The adjusted $R^{2}$ and predicted $R^{2}$ should be within approximately 0.20 of each other so as to be in agreement, or else setbacks may arise with either the data or the model. High $R^{2}$ value suggest there is a statistically significant interaction between factors. Resulting wear rate within the investigated ranges of parameters can be modeled by the final equation produced, Equation (5).

$$
\begin{aligned}
& \mathrm{W}_{\mathrm{r}}=0.037685-0.10651 \times \mathrm{FA}+0.054471 \times \mathrm{S}+0.019936 \times \mathrm{L}-0.001056 \times \mathrm{FA} \times \mathrm{S} \\
& -0.00337143 \times \mathrm{FA} \times \mathrm{L}+0.0000796096 \times \mathrm{S} \times \mathrm{L}+0.0070058 \times \mathrm{FA}^{2}-0.0000709692 \times \mathrm{S}^{2}+ \\
& 0.000880987 \times \mathrm{L}^{2}
\end{aligned}
$$

The order of the factors influencing the wear rate can be established through analysis of the F-value magnitude as follows: it can be observed the F-value of FA (837.432) was the most significant parameter having the highest statistical influence on the wear rate of AA6063-FA composites followed by applied load (483.037) and sliding speed (286.805) and S, which implies that the FA content has greater effect on wear rate value than the $\mathrm{L}$ and $\mathrm{S}$ factor.

Adequate precision ratio, which represent the signal-to-noise ratio, with values higher than 4 indicate adequate model discrimination [17]. It compares the range between the predicted values at 
the design points to the average prediction error. As shown in Table 7, the adequate ratio was 59.006, which indicates that the model has capacity of navigating the design space. The $\mathrm{R}^{2}$ value of about 0.9791 indicates the variability of the response was $97.91 \%$ about the mean which proved the model provide a good fit for the data. This fact alongside with the remarkable residual analysis led to the conclusion that the model given in Equation (5) can predict the wear rate of the compound within the investigated range of all three parameters.

Table 7. ANOVA results for the quadratic model of wear rate.

\begin{tabular}{|c|c|c|c|c|c|c|}
\hline & Sum of & & Mean & $\mathbf{F}$ & $p$-Value & \\
\hline Source & Squares & df & Square & Value & Prob $>$ F & \\
\hline Model & 292.32 & 9 & 32.48 & 213.39 & $<0.0001$ & Significant \\
\hline A-weight fraction & 127.46 & 1 & 127.46 & 837.43 & $<0.0001$ & \\
\hline B-sliding speed & 43.65 & 1 & 43.65 & 286.80 & $<0.0001$ & \\
\hline C-Load & 73.52 & 1 & 73.52 & 483.04 & $<0.0001$ & \\
\hline$A B$ & 1.36 & 1 & 1.36 & 8.96 & 0.0047 & \\
\hline$A C$ & 3.49 & 1 & 3.49 & 22.95 & $<0.0001$ & \\
\hline$B C$ & 0.20 & 1 & 0.20 & 1.30 & 0.2600 & \\
\hline$A^{2}$ & 0.48 & 1 & 0.48 & 3.18 & 0.0819 & \\
\hline$B^{2}$ & 0.35 & 1 & 0.35 & 2.33 & 0.1348 & \\
\hline$C^{2}$ & 3.17 & 1 & 3.17 & 20.83 & $<0.0001$ & \\
\hline Residual & 6.24 & 41 & 0.15 & & & \\
\hline Cor Total & 298.56 & 50 & & & & \\
\hline Std. Dev. & & 0.39 & \multicolumn{2}{|c|}{ R-squared } & & 0.9791 \\
\hline Mean & & 7.63 & \multicolumn{2}{|c|}{ Adj R-squared } & & 0.9745 \\
\hline C.V. \% & & 5.11 & \multicolumn{2}{|c|}{ Pred R-squared } & & 0.9658 \\
\hline PRESS & & 10.20 & \multicolumn{2}{|c|}{ Adequate Precision } & & 59.006 \\
\hline
\end{tabular}

Furthermore, in Table 7, both the $S L(B C)$ and $S^{2}\left(B^{2}\right)$ terms are considered to be insignificant as their $p$-value was greater than 0.05 . However, these terms were automatically added in order to support the model's hierarchy. In contrast, it is evident that the combined interaction of FA $\times$ L has the strongest effect on the response. The essential effects of the parameters on the responses, i.e., wear rate and the coefficient of friction, are further illustrated using contour lines and 3D surface plots.

Graphical Results of Wear Rate Model

Figure 1 presents the variance of collected data points about the linearized line which relates the predicted values with the actual values. This observation clearly indicates the model provide a good fit for the wear rate response.

Figure 2 further presents the perturbation plot of the wear rate data at the experimented mid values of the process parameters. The comparison of the effects of all three parameters at a specific area in the design range can be enabled by the perturbation plot. The response (wear rate) was graphically plotted by changing a single parameter over its investigated limits while other parameters were maintained constant. Similar to the significance of the $p$-value, this tool was also effective in identifying the interactive effects of parameters on the response [17]. The X-axis of the plot showed the relative position of the chosen levels of the parameters to the coded scale. The slopes of the curves showed the rate at which the parameter influenced the response. In Figure 2, the point selected in the design range was the central point (FA = $6 \mathrm{wt} \%, \mathrm{~S} 200 \mathrm{rpm}$ and $\mathrm{L} 49 \mathrm{~N})$. 


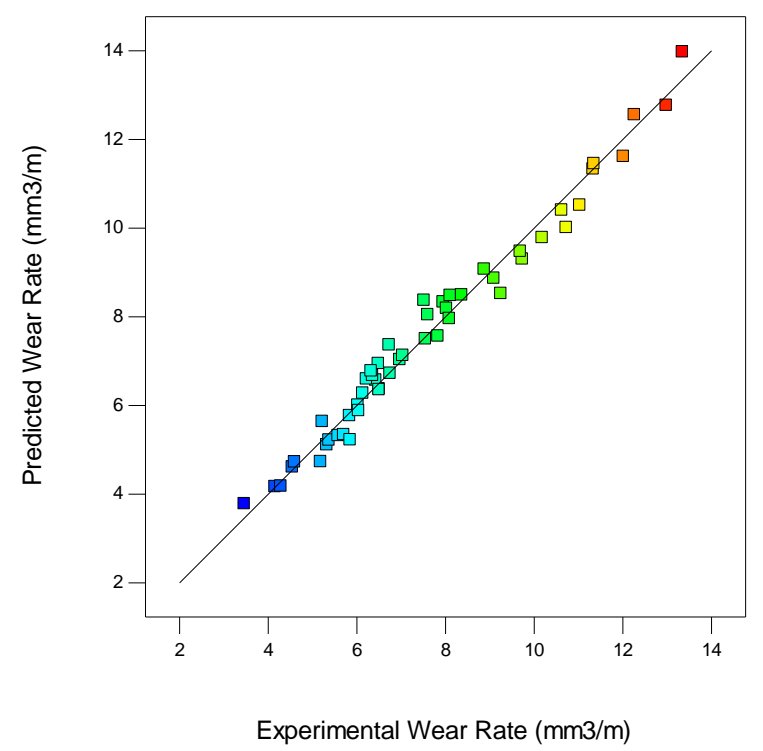

Figure 1. Experimental versus predicted wear rate $\mathrm{mm}^{3} / \mathrm{m}$.

Design-Expert ${ }^{\circledR}$ Softwar
Factor Coding: Actual
Wear rate $(\mathrm{mm} 3 / \mathrm{m})$
Actual Factors
A: weight fraction $=6$
B: sliding speed $=200$
C: Load $=49$

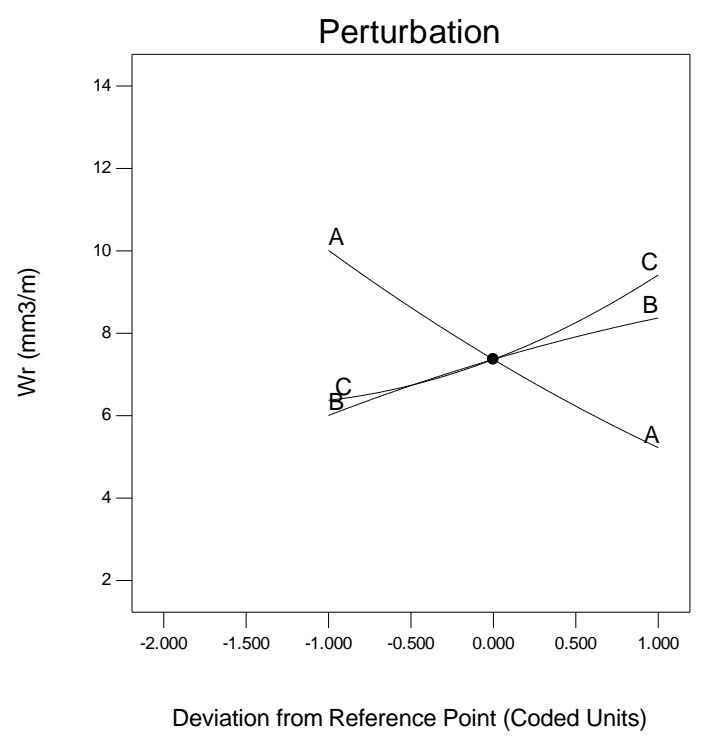

Figure 2. Perturbation plot of the effect of Fly ash content, sliding speed and applied load on wear rate of AA6063-FA composites.

The plot indicates that the fly ash content FA has the strongest inverse proportion (negative slope) on the wear rate while the load L has a smaller effect than FA, which was a direct proportional one (positive slope). The quadratic curves depicting the influence of the parameters on the wear rate were attributed to the quadratic terms in the model.

In summary, it is evident from Figure 2 that the FA content has negative effect on wear rate while both the applied load and sliding speed exhibit a positive impact on the wear rate. By increasing the FA content, the wear rate can be decreased while the opposite can be obtained when the applied load and sliding speed were increased. This trend was similar to that obtained from the experimental results.

The combined effects of two process parameters on the wear rate, while the third was kept constant, were further evaluated and these are demonstrated in Figures 3-5. As described earlier for the perturbation plot, the third parameter could be changed, but again, it was kept at similar value selected for the perturbation figure. The red spheres on the graphs represent the experimental data points. Moreover, it is evident, especially on the 3D plots, that these spheres have close location to the 
surfaces, which indicate that the model fits properly with the data points. With respect to the effects of the combined parameters, they portrayed similar findings to those presented in the perturbation plot. However, by identifying their effects relative to the numerical values of the response, they offer a visual aid in selecting the desired ranges of the parameters. Furthermore, they were important in the optimization process of the ranges of the processing parameters so as to meet certain response criteria. Owing to these facts and to avoid redundancy, only brief discussions were given for each figure as provided in the following paragraph.

Figure 3a shows the contour plot of the effect of $S$ and FA on the wear rate Wr. Each contour curve showed combinations of the two parameters that will predict a constant wear rate value. This wear rate value was observed inside the box situated at the middle of each contour curve. From the contour plot, $\mathrm{S}$ has a direct proportional effect on the predicted wear rate, while FA was inversely proportionate. The same data are further illustrated in 3D plot as shown in Figure 3b. The 3D plot has the added advantage of visual display of the effect of one of the parameter changes when the value of the other parameter is modified. For instance, consider the effect of $S$ at two different values of FA which were at 0 - and $12-w t \%$, it can be observed that the FA effect was stronger in the first case.
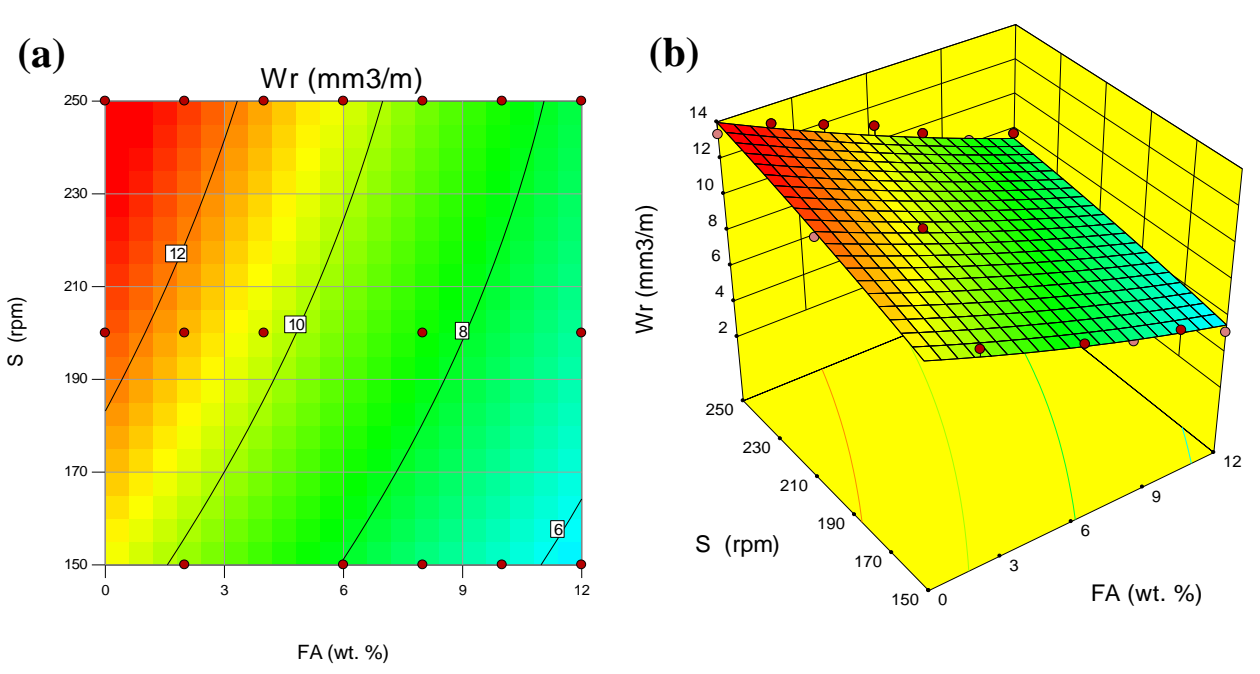

Figure 3. View of the interactive effect of FA and S on Wr, (a) contour lines 2D, (b) 3D.
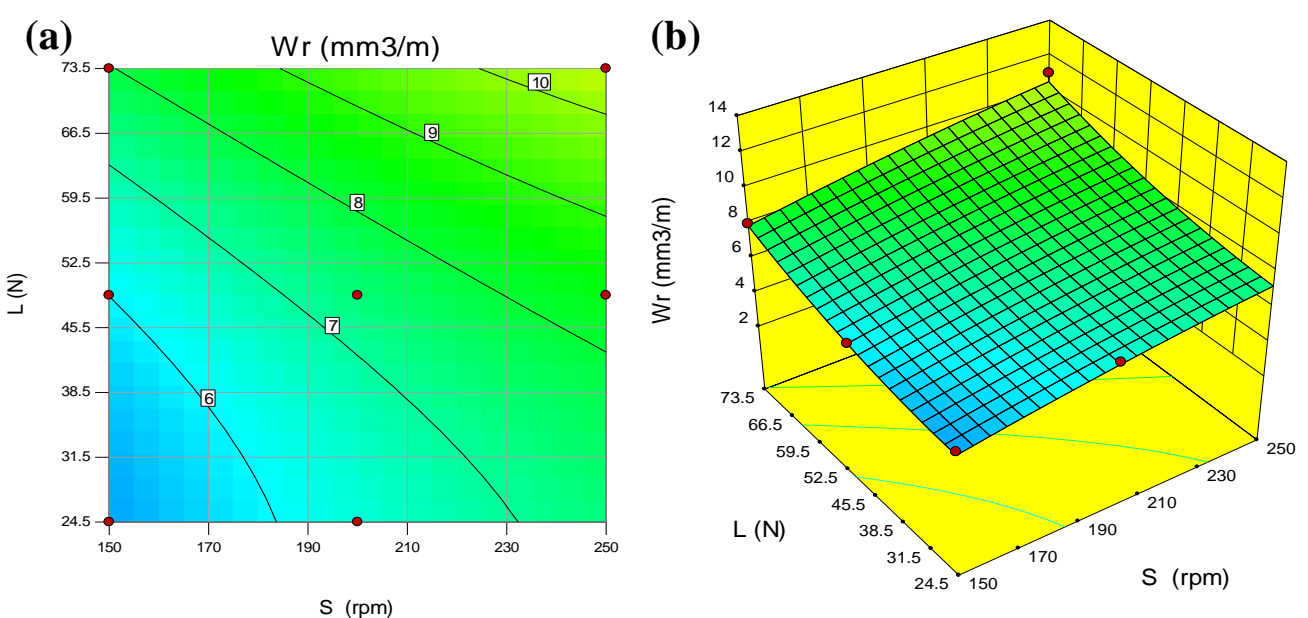

Figure 4. View of the interactive effect of $S$ and L on the Wr (a) contour lines 2D, (b) 3D. 
(a)

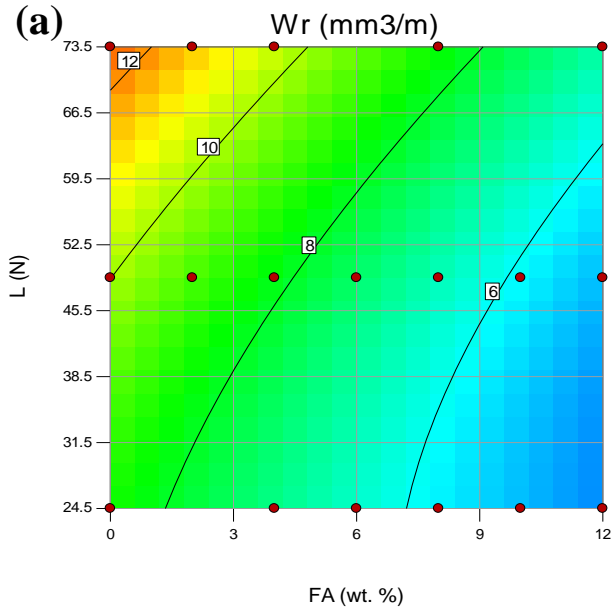

(b)

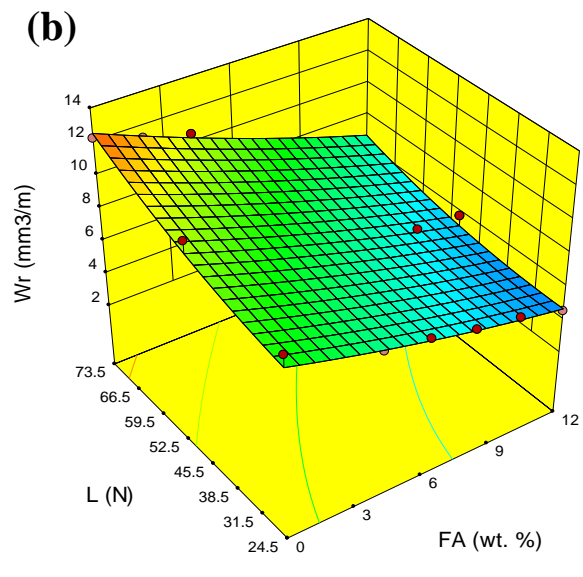

Figure 5. FA and $\mathrm{L}$ contour showing the interactive effect on $\mathrm{Wr}$, (a) contour lines, (b) 3D.

Figure 4a,b present that both $\mathrm{S}$ and $\mathrm{L}$ have directly proportional effects on the Wr. However, $\mathrm{L}$ has stronger effect than $\mathrm{S}$. This indicated that variations in $\mathrm{L}$ led to larger variations in the $\mathrm{Wr}$ than those emanating from large variations in $\mathrm{S}$.

Figure $5 \mathrm{a}, \mathrm{b}$ shows that FA has an inversely proportional effect on the $\mathrm{Wr}$, while $\mathrm{L}$ has a directly proportional effect. Similarly, FA has stronger effect on the response than L exhibits.

\subsection{Modeling and Analysis of Variance for Coefficient of Friction}

Likewise, the previous analyses described in Section 3.2 were repeated for the case of the coefficient of friction response. Again, the step-wise regression method was employed with the entire potential combinations of all three parameters and similarly too, the cubic terms were aliased for the ranges of the data obtained. The selection of the terms alongside the step wise regression method resulted in the elimination of the negligible model terms automatically [17]. Table 8 summarizes the computed ANOVA results with the variance for the Coefficient of friction model and all terms in the model.

Table 8. ANOVA for Response Surface Quadratic model (coefficient of friction model).

\begin{tabular}{|c|c|c|c|c|c|c|}
\hline Source & $\begin{array}{l}\text { Sum of } \\
\text { Squares }\end{array}$ & df & $\begin{array}{l}\text { Mean } \\
\text { Square }\end{array}$ & $\begin{array}{c}\text { F } \\
\text { Value }\end{array}$ & $\begin{array}{l}p \text {-Value } \\
\text { Prob > F }\end{array}$ & \\
\hline Model & 0.34 & 9 & 0.038 & 245.70 & $<0.0001$ & Significant \\
\hline A-Fly ash content & 0.19 & 1 & 0.19 & 1219.47 & $<0.0001$ & \\
\hline B-Load & 0.069 & 1 & 0.069 & 451.39 & $<0.0001$ & \\
\hline C-Sliding speed & 0.061 & 1 & 0.061 & 399.07 & $<0.0001$ & \\
\hline$A B$ & $6.376 \times 10^{-3}$ & 1 & $6.376 \times 10^{-3}$ & 41.61 & $<0.0001$ & \\
\hline$A C$ & $1.054 \times 10^{-3}$ & 1 & $1.054 \times 10^{-3}$ & 6.88 & 0.0122 & \\
\hline$B C$ & $5.305 \times 10^{-4}$ & 1 & $5.305 \times 10^{-4}$ & 3.46 & 0.0700 & \\
\hline$A^{2}$ & 0.010 & 1 & 0.010 & 66.91 & $<0.0001$ & \\
\hline$B^{2}$ & $1.049 \times 10^{-3}$ & 1 & $1.049 \times 10^{-3}$ & 6.85 & 0.0124 & \\
\hline$C^{2}$ & $2.273 \times 10^{-5}$ & 1 & $2.273 \times 10^{-5}$ & 0.15 & 0.7021 & \\
\hline Residual & $6.282 \times 10^{-3}$ & 41 & $1.532 \times 10^{-4}$ & & & \\
\hline Cor Total & 0.35 & 50 & & & & \\
\hline Std. Dev. & & 0.012 & & R-squared & & 0.9818 \\
\hline Mean & & 0.24 & & Adj R-squared & & 0.9778 \\
\hline C.V.\% & & 5.23 & & Pred R-squared & & 0.9699 \\
\hline PRESS & & 0.010 & & Adeq Precision & & 66.605 \\
\hline
\end{tabular}

In Table 8, it is shown that combined interaction of FA $\times$ L also had the strongest effects on the coefficient of friction. The effect of the parameters on the response is further demonstrated via the contour and 3D surface plots. The $\mathrm{S}^{2}$ and SL terms were proven to be insignificant as evidenced from 
the $p$-value which was greater than 0.05 . Nonetheless, this term again was also to support the model hierarchy. The step-wise regression method detected that this model term was insignificant however, it was necessary by other significant model terms. Moreover, in Table 8, the adequacy measures of $R^{2}$, adjusted $R^{2}$ and predicted $R^{2}$ were near to 1 ; they all agree well which is indicative of sufficient model [23]. The adequacy precision was greater than 4 which indicated sufficient model discrimination. In addition, this shows that the model has the capacity of navigating the design space [17]. The $\mathrm{R}^{2}$ value of approximately 0.9818 implies that around 98.18 of the data variability can be substantiated by model. Again, similarly to the wear rate, the model was proven to be a very good fit to the data and that the coefficient of friction, within the range of parameters investigated, can be predicted. Equation (6) presents the process model estimated from the experimental results within the range of parameters investigated.

$$
\begin{aligned}
& \mathrm{F}_{\mathrm{r}}=0.74823-0.040431 \times \mathrm{FA}-0.00516264 \times \mathrm{L}-0.00103544 \times \mathrm{S}+0.000144033 \times \mathrm{FA} \times \mathrm{L}+ \\
& 0.0000293612 \times \mathrm{FA} \times \mathrm{S}+0.00000411498 \times \mathrm{S} \times \mathrm{L}+ \\
& 0.00101923 \times \mathrm{FA}^{2}+0.0000160301 \times \mathrm{L}^{2}+0.00000056855 \times \mathrm{S}^{2}
\end{aligned}
$$

In summary, the model described by Equation (6) can provide good predictions of the coefficient of friction through any combinations of the fly ash content, sliding speed and load, within the range investigated.

\section{Graphical Results of Coefficient of Friction}

Figure 6 presents the variance of data points about the linearized line relating the actual and predicted values, which is an indication of the good fitness value of the model.

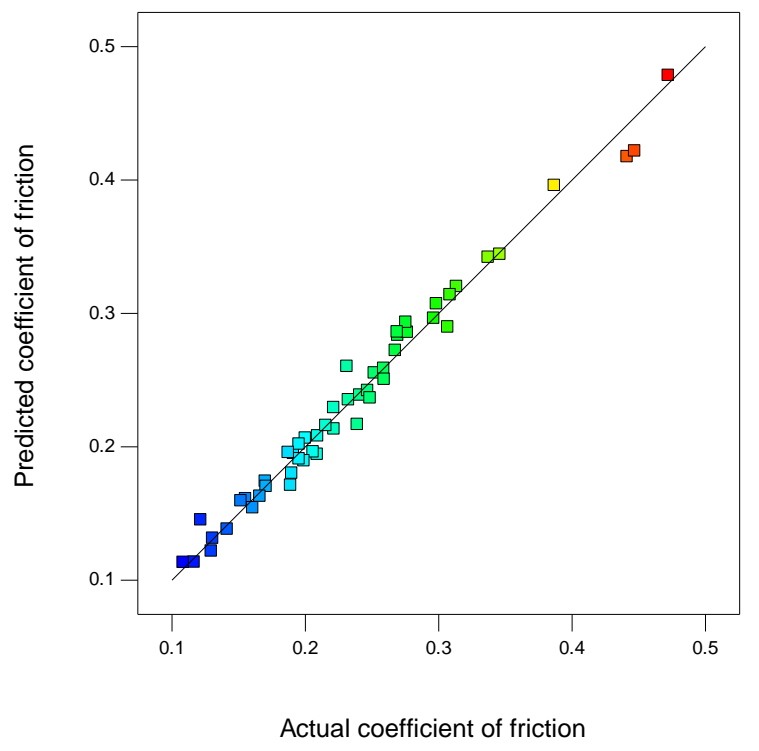

Figure 6. Actual versus predicted scattering of the data points.

For the process parameters, the perturbation (see Figure 7) was obtained at a similar point of location (FA $=6 \mathrm{wt} \%, \mathrm{~S} 200 \mathrm{rpm}$ and L $49 \mathrm{~N}$ ). From the figure, it is evident that FA has inversely proportional effect and has the maximum effect on the coefficient of friction. The second maximum effect was owing to $\mathrm{L}$ which also had an inversely proportional effect on the coefficient of friction. The sliding speed also exhibited an inversely proportional effect. 


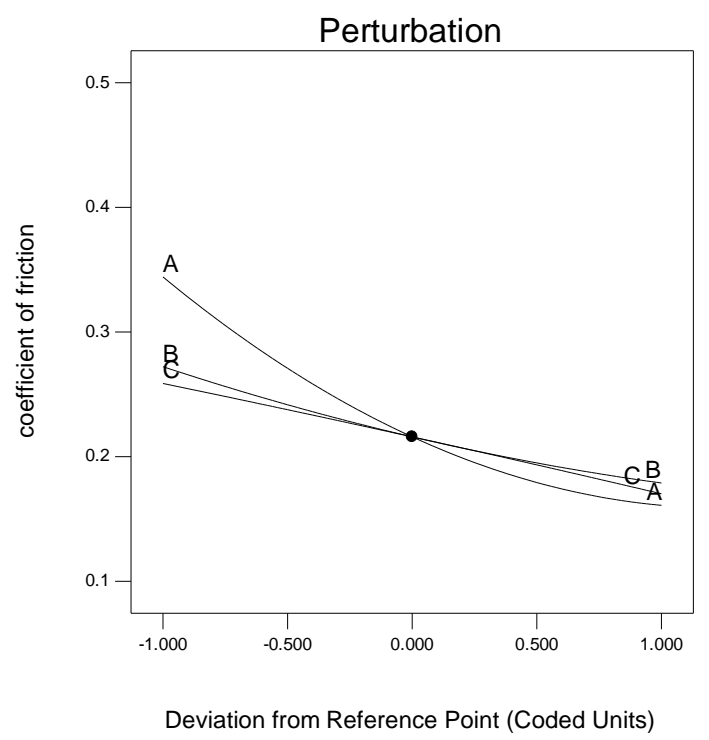

Figure 7. Perturbation plot of the process control variables' effects on the coefficient of friction.

The following Figures 8-10, present the combined influences of two parameters, at a time on $\mathrm{F}_{\mathrm{r}}$. the design points are represented by the red spheres on the graphs; their locations on the 3D plots was a confirmation that both the model and the data points have a good fit. The contour plot for the influence of $\mathrm{FA}$ and $\mathrm{S}$ on $\mathrm{F}_{\mathrm{r}}$ is presented in Figure 8a. It is evident from the contour plot that $S$ and FA have an inversely proportional effect on $\mathrm{F}_{\mathrm{r}}$. It can be observed from the $3 \mathrm{D}$ plot in Figure $8 \mathrm{~b}$ that as FA and $S$ decrease the $F_{r}$ decreases. By employing the combination of low $S$ and low FA settings, the deepest $F_{r}$ values were generated, while holding $L$ constant, in this case at its mid-range $=49 \mathrm{~N}$.
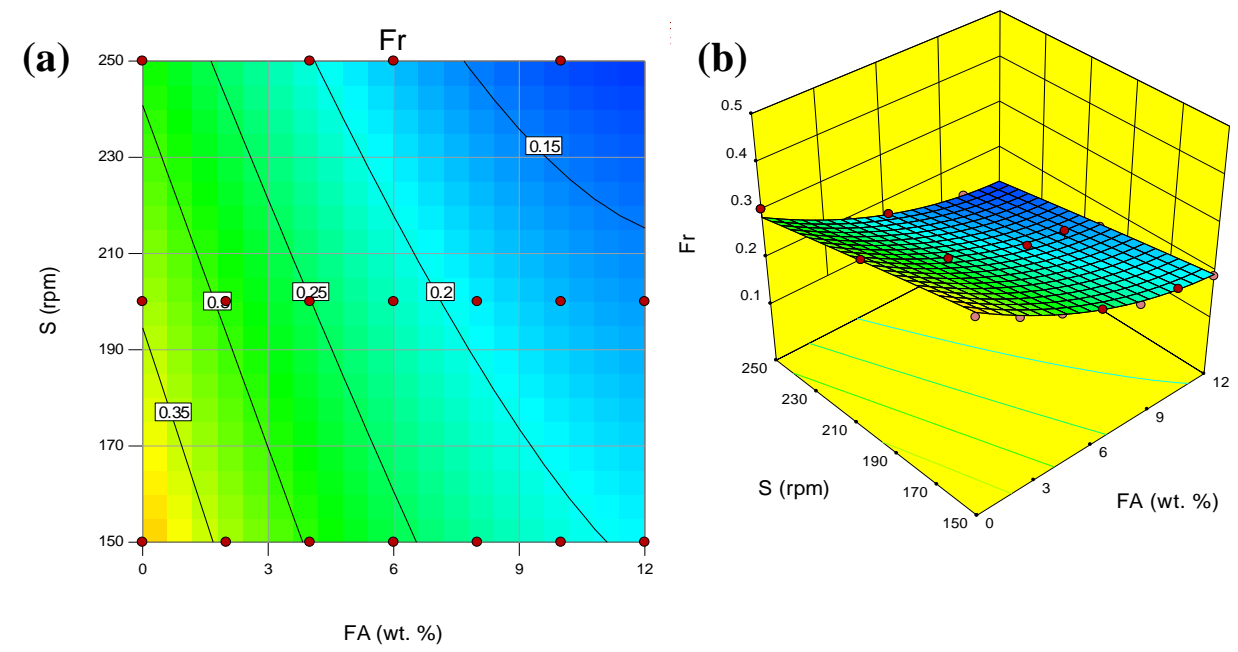

Figure 8. View of the interactive effect of FA and S on Fr, (a) contour lines 2D, (b) 3D. 
(a)

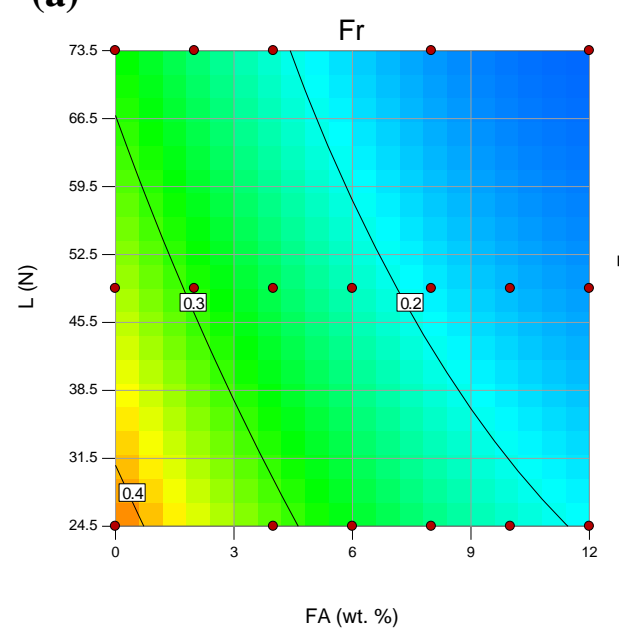

(b)

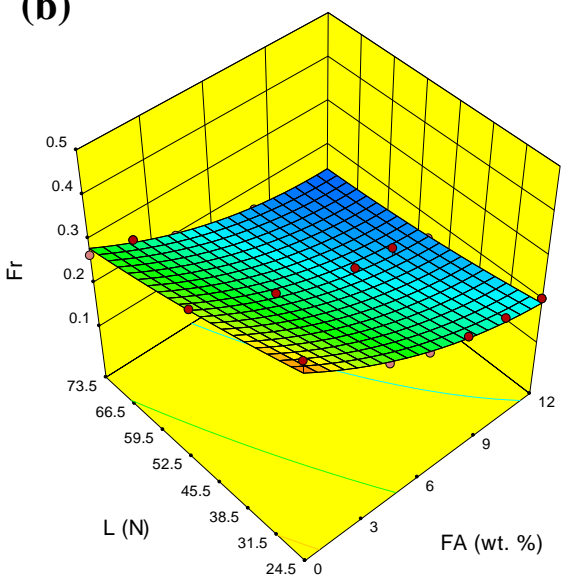

Figure 9. FA and L contour showing the interactive effect on the Fr, (a) contour lines 2D, (b) 3D.

(a)

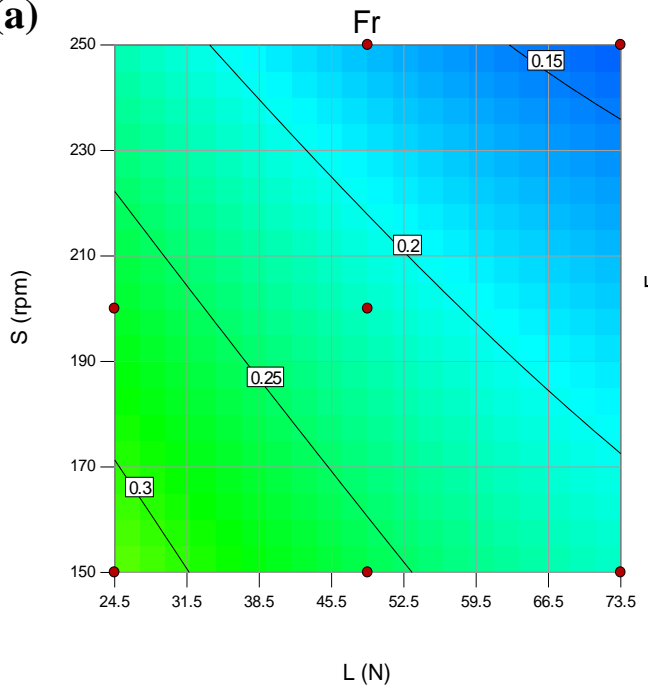

(b)

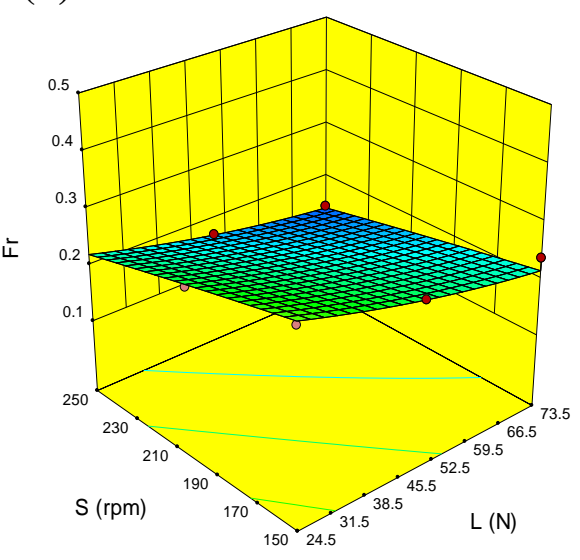

Figure 10. View of the interactive effect of $S$ and $L$ on $F_{r},(a)$ contour lines 2D, (b) 3D.

Figure $9 a, b$ indicates that both FA and $L$ have an inversely proportional influence on the $F_{r}$. Nonetheless, FA exhibited stronger effect than L. Slight changes in FA often affect the $F_{r}$ in a magnitude greater than changes caused by even large changes in $\mathrm{L}$.

Figure $10 \mathrm{a}, \mathrm{b}$ shows that $\mathrm{S}$ and $\mathrm{L}$ have an inversely proportional effect on the $\mathrm{F}_{\mathrm{r}}$. In a similar way, $\mathrm{S}$, which can be evidenced from the slopes of the contour lines and 3D surface, almost exhibited equal to $L$ effect on the $\mathrm{F}_{\mathrm{r}}$.

\subsection{Validation of the Statistical Models}

The wear rate and coefficient of friction were numerically modeled by RSM based on FA content, applied load and sliding speed. Thereafter, the statistical model was validated with a dataset, $20 \%$ from the experimental data were used in the process of models building to verify the produced models and find the reliability of the model and the measured responses were recorded. The predicted wear rate and coefficient of friction calculated by Equations (5) and (6) were plotted against experimental data in Figures 11 and 12. The figures indicated that the surface response method model provides excellent coincidence with experimental value with R-squared value of 0.9665 and 
0.9893 respectively. These results were expected due to the high order model used in SRM which provide more accurate response.

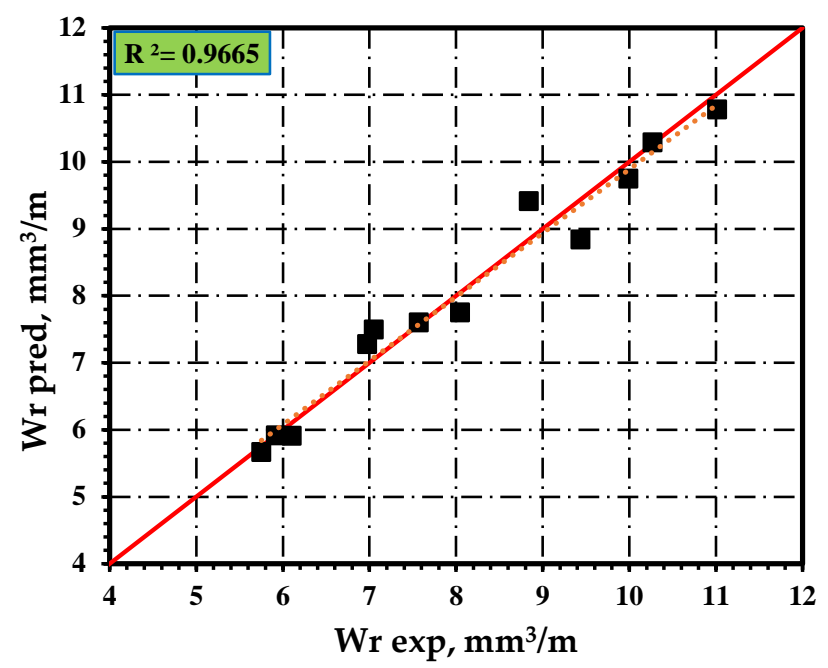

Figure 11. SRM-predicted wear rate versus experimental results.

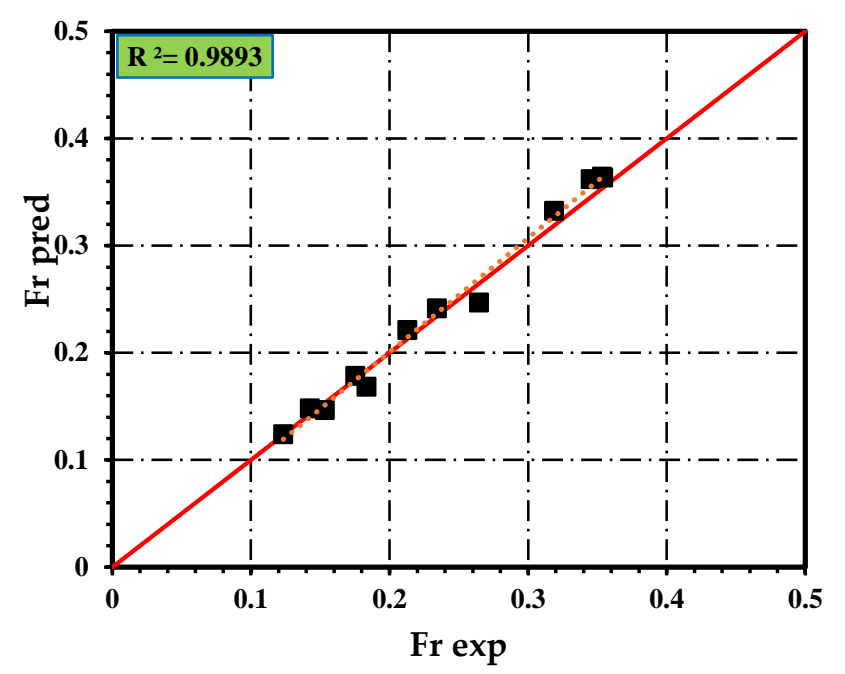

Figure 12. SRM-predicted coefficient of friction versus experimental results.

\section{Conclusions}

AA6063 alloy-based aluminum matrix composites with FA particles have been successfully fabricated with compocasting technique. The overall results revealed that the wear resistance of the composites was positively enhanced by the inclusion of the FA particles. The wear resistance enhancement was attributed to increased hardness, generation of strain fields, homogenous distribution, spherical shape of FA particles and reduction in effective contact area. Increasing FA content restricted the deformation of the matrix material. The wear rates of the composites were increased by the applied load. FA content exhibited an inversely proportional relationship with wear rate, coefficient of friction and friction force for AA6063-FA composites. Increasing the sliding speed increased the wear rate but decreased the coefficient of friction and friction force of composites. In addition, the wear rate and fractional force of composites increased with increasing applied load, but coefficient of friction varied inversely with applied load. These control parameters were then employed to build statistical models for the wear rate and coefficient of friction. FA had the highest statistical influence on the wear rate and coefficient of friction of AA6063-FA composites followed by applied load and sliding speed. Moreover, FA content with applied load exhibited the strongest interaction effects. Finally, AA6063 
aluminum matrix composites reinforced with FA can be used in applications that require excellent wear resistance.

Author Contributions: The research conceptualization and methodology are contributed by A.M.R., D.L.M. and U.M.B.; the experimental and numerical works including the data curation are performed by A.M.R. and U.M.B.; the results analysis and interpretation are conducted by A.M.R., D.L.M., U.M.B. and M.R.I.; the preparation of the original draft, reviews and editing are contributed by A.M.R. and D.L.M. and lastly the project administration, supervision and funding are managed by D.L.M. All authors have read and agreed to the published version of the manuscript.

Funding: The authors would like to acknowledge the financial support from the Ministry of Education Malaysia with reference code FRGS/1/2019/STG07/UPM/02/10 and Vot No. 5540209.

Conflicts of Interest: The authors declare no conflict of interest. The funders had no role in the design of the study; in the collection, analyses, or interpretation of data; in the writing of the manuscript, or in the decision to publish the results.

\section{Nomenclature}

\begin{tabular}{|c|c|}
\hline $\min$ & Minute \\
\hline rpm & Revolution per minute \\
\hline ASTM & American Society for Testing and Materials \\
\hline FA & Fly ash \\
\hline $\mathrm{Al}$ & Aluminum \\
\hline AA6063 & AA6063 aluminum alloy \\
\hline AA6063-FA & AA6063 aluminum alloy-fly ash composites \\
\hline MMCs & Metal matrix composites \\
\hline AMCs & Aluminum matrix composites \\
\hline AMMCs & Aluminum metal matrix composites \\
\hline Al-FA & Aluminum-fly ash \\
\hline $\mathrm{B} 4 \mathrm{C}$ & Boron carbide \\
\hline Graphite & Gr \\
\hline XRD & X-ray diffraction \\
\hline XRF & X-ray fluorescence \\
\hline ANOVA & Analysis of variance \\
\hline RSM & Response surface method \\
\hline DRAMCs & Discontinuously reinforced aluminum matrix composites \\
\hline DOE & Design of experimental \\
\hline CCD & Based central composite design \\
\hline SS & Semisolid-semisolid \\
\hline SL & Semisolid-liquid \\
\hline $\mathrm{Wr}$ & Wear rate $(\mathrm{mm} 3 / \mathrm{m})$ \\
\hline $\mathrm{Fr}$ & Coefficient of friction \\
\hline$\mu$ & The coefficient of friction \\
\hline FT & Tangential force $(\mathrm{N})$ \\
\hline $\mathrm{FN}$ & Normal force $(\mathrm{N})$ \\
\hline $\mathrm{V}$ & Volume loss (mm3) \\
\hline S & Sliding speed (rpm) \\
\hline $\mathrm{L}$ & Applied load (N) \\
\hline Wrp & Predicted wear rate \\
\hline Frp & Predicted coefficient of friction \\
\hline Wre & Experimental wear rate \\
\hline Fre & Experimental coefficient of friction \\
\hline Wra & Average of experimental wear rate \\
\hline Fra & Average of experimental coefficient of friction \\
\hline vol\% & Percentage of volume fraction \\
\hline$w t \%$ & Percentage of weight fraction \\
\hline
\end{tabular}




\section{Appendix A}

Table A1. Parameters used in mathematical models for wear analysis.

\begin{tabular}{|c|c|c|c|c|c|}
\hline NO & FA wt $\%$ & Load N & Sliding Speed Rpm & Wear Rate $\mathrm{mm}^{3} / \mathrm{m}$ & Coefficient of Friction \\
\hline 1 & 0 & 24.5 & 150 & 6.4867 & 0.4723 \\
\hline 2 & 0 & 24.5 & 200 & 9.25 & 0.4471 \\
\hline 3 & 0 & 24.5 & 250 & 9.9889 & 0.3451 \\
\hline 4 & 0 & 49 & 150 & 7.9484 & 0.3868 \\
\hline 5 & 0 & 49 & 200 & 10.7283 & 0.346 \\
\hline 6 & 0 & 49 & 250 & 11.3323 & 0.3069 \\
\hline 7 & 0 & 73.5 & 150 & 11.0173 & 0.3187 \\
\hline 8 & 0 & 73.5 & 200 & 12.2625 & 0.269 \\
\hline 9 & 0 & 73.5 & 250 & 13.3471 & 0.2486 \\
\hline 10 & 2 & 24.5 & 150 & 6.136 & 0.4414 \\
\hline 11 & 2 & 24.5 & 200 & 8.0448 & 0.3541 \\
\hline 12 & 2 & 24.5 & 250 & 9.0934 & 0.2985 \\
\hline 13 & 2 & 49 & 150 & 7.5484 & 0.3372 \\
\hline 14 & 2 & 49 & 200 & 8.875628 & 0.2755 \\
\hline 15 & 2 & 49 & 250 & 10.2673 & 0.2344 \\
\hline 16 & 2 & 73.5 & 150 & 10.1834 & 0.2766 \\
\hline 17 & 2 & 73.5 & 200 & 11.3503 & 0.2468 \\
\hline 18 & 2 & 73.5 & 250 & 12.9839 & 0.1873 \\
\hline 19 & 4 & 24.5 & 150 & 5.7524 & 0.3533 \\
\hline 20 & 4 & 24.5 & 200 & 6.9738 & 0.3086 \\
\hline 21 & 4 & 24.5 & 250 & 7.6022 & 0.2313 \\
\hline 22 & 4 & 49 & 150 & 6.7511 & 0.2963 \\
\hline 23 & 4 & 49 & 200 & 8.0254 & 0.2592 \\
\hline 24 & 4 & 49 & 250 & 9.7357 & 0.1954 \\
\hline 25 & 4 & 73.5 & 150 & 9.4389 & 0.2647 \\
\hline 26 & 4 & 73.5 & 200 & 10.6226 & 0.2001 \\
\hline 27 & 4 & 73.5 & 250 & 12.0139 & 0.166 \\
\hline 28 & 6 & 24.5 & 150 & 5.3246 & 0.3135 \\
\hline 29 & 6 & 24.5 & 200 & 6.504 & 0.2676 \\
\hline 30 & 6 & 24.5 & 250 & 6.974 & 0.2129 \\
\hline 31 & 6 & 49 & 150 & 6.0267 & 0.2589 \\
\hline 32 & 6 & 49 & 200 & 6.7292 & 0.2155 \\
\hline 33 & 6 & 49 & 250 & 7.5166 & 0.1707 \\
\hline 34 & 6 & 73.5 & 150 & 8.0876 & 0.2391 \\
\hline 35 & 6 & 73.5 & 200 & 8.8426 & 0.1754 \\
\hline 36 & 6 & 73.5 & 250 & 11.0318 & 0.1415 \\
\hline 37 & 8 & 24.5 & 150 & 4.5472 & 0.2694 \\
\hline 38 & 8 & 24.5 & 200 & 5.83851 & 0.2409 \\
\hline 39 & 8 & 24.5 & 250 & 6.4298 & 0.1954 \\
\hline 40 & 8 & 49 & 150 & 5.7058 & 0.2214 \\
\hline 41 & 8 & 49 & 200 & 6.2207 & 0.1991 \\
\hline 42 & 8 & 49 & 250 & 7.0522 & 0.1535 \\
\hline 43 & 8 & 73.5 & 150 & 7.0393 & 0.209 \\
\hline 44 & 8 & 73.5 & 200 & 8.1105 & 0.1518 \\
\hline 45 & 8 & 73.5 & 250 & 9.6893 & 0.1296 \\
\hline 46 & 10 & 24.5 & 150 & 4.1575 & 0.2518 \\
\hline 47 & 10 & 24.5 & 200 & 5.3748 & 0.2216 \\
\hline 48 & 10 & 24.5 & 250 & 5.9217 & 0.1835 \\
\hline 49 & 10 & 49 & 150 & 5.1829 & 0.2093 \\
\hline 50 & 10 & 49 & 200 & 6.0414 & 0.1891 \\
\hline 51 & 10 & 49 & 250 & 6.3559 & 0.1306 \\
\hline 52 & 10 & 73.5 & 150 & 6.5035 & 0.1899 \\
\hline 53 & 10 & 73.5 & 200 & 7.5705 & 0.1427 \\
\hline 54 & 10 & 73.5 & 250 & 8.367 & 0.1167 \\
\hline 55 & 12 & 24.5 & 150 & 3.4623 & 0.2324 \\
\hline
\end{tabular}


Table A1. Cont.

\begin{tabular}{cccccc}
\hline NO & FA $\mathbf{~ w t} \%$ & Load N & Sliding Speed Rpm & Wear Ratemm $\mathbf{3} / \mathbf{m}$ & Coefficient of Friction \\
\hline 56 & 12 & 24.5 & 200 & 4.598 & 0.2059 \\
57 & 12 & 24.5 & 250 & 5.58011 & 0.1607 \\
58 & 12 & 49 & 150 & 4.2891 & 0.1912 \\
59 & 12 & 49 & 200 & 5.8519 & 0.1553 \\
60 & 12 & 49 & 250 & 6.1012 & 0.1234 \\
61 & 12 & 73.5 & 150 & 5.221376 & 0.1701 \\
62 & 12 & 73.5 & 200 & 6.3248 & 0.1217 \\
63 & 12 & 73.5 & 250 & 7.8319 & 0.1085 \\
\hline
\end{tabular}

\section{References}

1. Sardar, S.; Pradhan, S.K.; Karmakar, S.K.; Das, D. Modeling of abraded surface roughness and wear resistance of aluminum matrix composites. J. Tribol. 2019, 141, 071601. [CrossRef]

2. Nouri, M.; Abdollah-Zadeh, A.; Malek, F. Effect of welding parameters on dilution and weld bead geometry in cladding. J. Mater. Sci. Technol. 2007, 23, 817.

3. Palanivel, R.; Mathews, P.K.; Murugan, N. Development of mathematical model to predict the mechanical properties of friction stir welded AA6351 aluminum alloy. J. Eng. Sci. Technol. Rev. 2011, 44, 25-31. [CrossRef]

4. Heidarzadeh, A.; Saeid, T.; Khodaverdizadeh, H.; Mahmoudi, A.; Nazari, E. Establishing a mathematical model to predict the tensile strength of friction stir welded pure copper joints. Metall. Mater. Trans. B 2013, 44, 175-183.

5. Lakshminarayanan, A.; Balasubramanian, V. Comparison of RSM with ANN in predicting tensile strength of friction stir welded AA7039 aluminium alloy joints. Trans. Nonferrous Met. Soc. China 2009, 19, 9-18. [CrossRef]

6. Kumar, K.R.; Mohanasundaram, K.M.; Arumaikkannu, G.; Subramanian, R. Analysis of parameters influencing wear and frictional behavior of aluminum-Fly ash composites. Tribol. Trans. 2012, 55, 723-729. [CrossRef]

7. Rajmohan, T.; Palanikumar, K.; Ranganathan, S. Evaluation of mechanical and wear properties of hybrid aluminium matrix composites. Trans. Nonferr. Met. Soc. China 2013, 23, 2509-2517. [CrossRef]

8. Magibalan, S.; Senthilkumar, P.; Palanivelu, R.; Senthilkumar, C.; Shivasankaran, N.; Prabu, M. Dry sliding behavior of aluminum alloy 8011 with $12 \%$ fly ash composites. Mater. Res. Express 2018, 5, 056505. [CrossRef]

9. Mandal, N.; Roy, H.; Mondal, B.; Murmu, N.C.; Mukhopadhyay, S. Mathematical modeling of wear characteristics of 6061 Al-alloy-SiCp composite using response surface methodology. J. Mater. Eng. Perform. 2012, 21, 17-24.

10. Monikandan, V.V.; Jacob, J.C.; Joseph, M.A.; Rajendrakumar, P. Statistical analysis of tribological properties of aluminum matrix composites using full factorial design. Trans. Indian Inst. Met. 2015, 68, 53-57. [CrossRef]

11. Moses, J.J.; Dinaharan, I.; Jekhar, S.J. Prediction of influence of process parameters on tensile strength of AA6061/TiC aluminum matrix composites produced using stir casting. Trans. Nonferr. Met. Soc. China 2016, 26, 1498-1511. [CrossRef]

12. Razzaq, A.M.; Majid, D.L.; Ishak, M.R.; Uday, M.B. Microstructural characterization of fly ash particulate reinforced AA6063 aluminium alloy for aerospace applications. Mater. Sci. Eng. Conf. Ser. 2017, 270, 1.

13. Razzaq, A.M.; Majid, D.L.; Ishak, M.R.; Uday, M.B. Influence of fly ash on the microstructure and mechanical properties of AA6063 alloy using compocasting technique. Mater. Express 2019, 9, 1-14. [CrossRef]

14. Razzaq, A.M.; Majid, D.L.; Manan, N.H.; Ishak, M.R.; Uday, M.B. Effect of fly ash content and applied load on wear behaviour of AA6063 aluminium alloy. In IOP Conference Series: Materials Science and Engineering; IOP Publishing: Bristol, UK, 2018.

15. Razzaq, A.M.; Majid, D.L.; Ishak, M.R.; Uday, M.B. Effects of Solid Fly Ash on Wear Behaviour of AA6063 Aluminum Alloy; Elsevier: Amsterdam, The Netherlands, 2019.

16. Razzaq, A.M.; Majid, D.L.; Ishak, M.R.; Uday, M.B. Effect of fly ash addition on the physical and mechanical properties of AA6063 alloy reinforcement. Metals 2017, 77, 477. [CrossRef]

17. Design-Expert Software. User's Guide, Technical Manual; Stat-Ease Inc.: Minneapolis, MN, USA, 2000; Volume 6. 
18. Kumar, S.; Balasubramanian, V. Effect of reinforcement size and volume fraction on the abrasive wear behaviour of AA7075 Al/SiC p P/M composites-A statistical analysis. Tribol. Int. 2010, 43, 414-422. [CrossRef]

19. Balasubramanian, V.; Lakshminarayanan, A.K.; Varahamoorthy, R.; Babu, S. Application of response surface methodolody to prediction of dilution in plasma transferred arc hardfacing of stainless steel on carbon steel. J. Iron Steel Res. Int. 2009, 16, 44-53. [CrossRef]

20. Elangovan, K.; Balasubramanian, V.; Babu, S. Predicting tensile strength of friction stir welded AA6061 aluminium alloy joints by a mathematical model. Mater. Des. 2009, 30, 188-193. [CrossRef]

21. Gopalakrishnan, S.; Murugan, N. Production and wear characterisation of AA 6061 matrix titanium carbide particulate reinforced composite by enhanced stir casting method. Compos. Part B Eng. 2012, 43, 302-308. [CrossRef]

22. Kumar, S.; Balasubramanian, V. Developing a mathematical model to evaluate wear rate of AA7075/SiC p powder metallurgy composites. Wear 2008, 264, 1026-1034. [CrossRef]

23. Badkar, D.S.; Pandey, K.S.; Buvanashekaran, G. Development of RSM-and ANN-based models to predict and analyze the effects of process parameters of laser-hardened commercially pure titanium on heat input and tensile strength. Int. J. Adv. Manuf. Technol. 2013, 65, 1319-1338. [CrossRef]

(C) 2020 by the authors. Licensee MDPI, Basel, Switzerland. This article is an open access article distributed under the terms and conditions of the Creative Commons Attribution (CC BY) license (http://creativecommons.org/licenses/by/4.0/). 